\title{
Groundwater Quality Index Assessment using the Entropy Method on the Nineveh Plain in Northern Iraq
}

\author{
Ali Z. Al-Ozeer ${ }^{1}$ and Alaa M. Al-Abadi ${ }^{1, *}$ \\ Department of Geology, College of Science, University of Basrah, Basrah, Iraq. \\ * Correspondence: alaa.atiaa@uobasrah.edu.iq
}

\begin{abstract}
Received:

28 August 2021

Accepted:

6 November 2021

Human health is greatly and directly affected by the quality of groundwater and the extent of its pollution. This research evaluated the quality of groundwater in the Nineveh plain in northern Iraq and determined the suitability of groundwater for drinking purposes. Sixty-nine groundwater samples were taken and the major physical and chemical constituents, including pH, TDS, EC, $\mathrm{Ca}_{2}{ }^{+}, \mathrm{Mg}^{+}, \mathrm{Na}^{+}, \mathrm{K}^{+}, \mathrm{Cl}^{-}, \mathrm{So}_{4}{ }^{2-}, \mathrm{HCO}_{3}{ }^{-}$, and $\mathrm{NO}_{3}{ }^{-}$. were analyzed to use in

Published: calculating groundwater quality index for drinking purpose based on the World Health

31 January 2022 Organization standards for the year 2017. To prevent subjectively assigning weights in the calculation groundwater quality index, the entropy information theory was used. The estimated groundwater quality index values were loaded into ArcGIS 10.8 as a point, shapefile and interpolated using Empirical Bayesian Kriging techniques to produce the final groundwater quality index map of the study area. Results indicated that the entropy groundwater quality index for $2.9 \%$ of the samples were within the excellent range, $33 \%$ were in the good range, $14.5 \%$ were within the moderate range. The groundwater quality index values range between (48-581.8). These values were manually classified into five categories: $>200$ (very poor), 200-150 (poor), 150-100 (moderate), 100-50 (good), and <50 (excellent). The study discovered that the excellent class occupies $0.2 \%\left(50.9 \mathrm{~km}^{2}\right)$ of the study area, while the good class occupies $23.4 \%\left(596 \mathrm{~km}^{2}\right)$, the medium class occupies $18.6 \%(473.7$ $\left.\mathrm{km}^{2}\right)$, and the poor and extremely poor classes occupy $26.1 \%\left(664.8 \mathrm{~km}^{2}\right)$ and $31.7 \%(807$ $\mathrm{km}^{2}$ ), respectively.
\end{abstract}

Keywords: Groundwater Quality index; Entropy; Nineveh Plain; Iraq

\section{Introduction}

The quality and availability of water are important indicators of sustainable development, based on the great role that water plays in economic development, and it has come to be seen as a rare commodity that must be preserved. The United Nations has developed the right to water within a set of indicators based on three main elements: water availability, water quality, and accessibility, the ability to access water (Gain et al. 2016). In recent decades, because of rapid population growth and increased industrialization, the demand for freshwater has increased (Jiang, 2009). Quick and unplanned development has led to freshwater contamination, particularly in relation to groundwater supply and quality, and over-use and inappropriate waste disposal (Mateo-Sagasta et al., 2017). The quality of groundwater depends on several variables, including water quality that recharges groundwater,

DOI: $\underline{10.46717 / \text { igj.55.1A.10Ms-2022-01-29 }}$ 
precipitation and geochemical processes at the surface and subsurface (Anderson et al., 2015). Temporal changes, changes in human activities, hydrogeological and geological factors all cause cyclical changes in water quality (Lintern et al., 2018). Inadequate measures to protect the environment within the industrial fields, landfill sites, fertilizer factories, cement, and rubber, all of which led to a deterioration in water quality and an increase in pollution (Chatterjee, et al., 2010). Because they transfer and absorb pollutants, river basins are particularly vulnerable to pollution from human activities, sewage systems, industrial and agricultural waste (Awadh and Ahmed, 2013). As a result, water quality must be maintained, and surface and groundwater pollution must be controlled because pollution not only harms human health but also harms economic and social development (Giri, 2020; and Awadh et al., 2021). Once groundwater is exposed to pollution, it becomes difficult to treat or stop this pollution to restore groundwater quality. For this reason, it is necessary to conduct periodic water quality monitoring and activate methods and means of protection for it (Talabi and Kayode, 2019). The objective of monitoring groundwater quality and developing guidelines is to ensure that all people within a country or any geographical location in its present and future have access to safe drinking water. There are several techniques for determining the quality of water currently available such as, membership degree method, analytic hierarchy process method, factor analysis method, and fuzzy mathematics method (Pei-Yue, Hui and Jian-Hua, 2010). However, these methodologies do not take into account different types of water contamination since they are unable to identify all elements and their level of influence on the evaluation in order to meet functional area criteria, Therefore, groundwater quality index GWQI) By entropy method was used to achieve this goal. The GWQI has been used in many studies to give a single value for the evaluation of water quality for drinking purposes such as (Rashid et al., 2016; Fatah et al., 2020; Beg et al., 2021). The groundwater quality index (GWQI) is employed in this study to assess the quality of the groundwater. GWQI is a ranking process that has a composite influence on the overall quality of the groundwater in each parameter of water quality. It is an effective method for delimiting the efficiency and suitability of groundwater for drinking use (Reza and Singh, 2010). To provide an overview of the status of groundwater quality for drinking, the GWQI was applied to evaluate the groundwater quality in the Nineveh Plain, which represents a single number that is used to indicate the groundwater quality in terms of both spatial and temporal variation. Use the WHO (2017) in Al-Abadi et al. (2021) to evaluate the quality and the suitability of the groundwater in the Nineveh plains.

\section{The Study Area}

The Nineveh Plain is situated in northern Iraq, between the latitudes of $36^{\circ} 47^{\prime} 27.47^{\prime \prime} \mathrm{N}$ and $35^{\circ} 59^{\prime} 3.57^{\prime \prime} \mathrm{N}$ and the longitudes of $42^{\circ} 44^{\prime} 33.51^{\prime \prime} \mathrm{E}$ and $43^{\circ} 33^{\prime} 33.91$ 'E, in the eastern part of the Mosul governorate. It encompasses a large area $(2450 \mathrm{~km} 2)$. It stretches from Mosul Lake in the North to the Great Zab River in the South. It is bordered by the Tigris River from the western side (Fig.1). The study area's highest point $(1047 \mathrm{~m})$ is located in the northeastern region, within the Alqoosh and Ain Sifni anticlines, (Fig. 1). The elevation begins to decrease towards the southwest and the lowest elevation $(190 \mathrm{~m})$ is observed in the river basin. The ground surface in the middle and south is generally flat, whereas the north and northeast have some hills and valleys. The exposed formations in the research area range in age from the Middle-Upper Eocene to the Quaternary (Ahmad, 1980; Ameen, 2006; Al-Jiburi, 2007). In the south and middle of the research area, the youngest formations emerge whereas the older formations occur within the fold areas in the north and northeast of the study. The northern and northeastern portions of the study region contain numerous complex structures, which are represented by many folds (Mustafa and Alian, 2013; Hussein1 and Al-Salem, 2017; Al-Jumaily and Al-Azzawi, 2018), (Fig.2a). It also has several major faults, joints, and cracks that are evident near the folds. The axes of the folds represent water divides. The exposure of many geological formations is on the wings of these folds; therefore, these places serve as recharge points for groundwater, particularly the Pila Spi 
Formation, which features joints and cracks in the eastern area (Mutib and Al-shaikh, 2005). The annual average of rainfall is $333.64 \mathrm{~mm}$ per year (Alozeer et al., 2020).

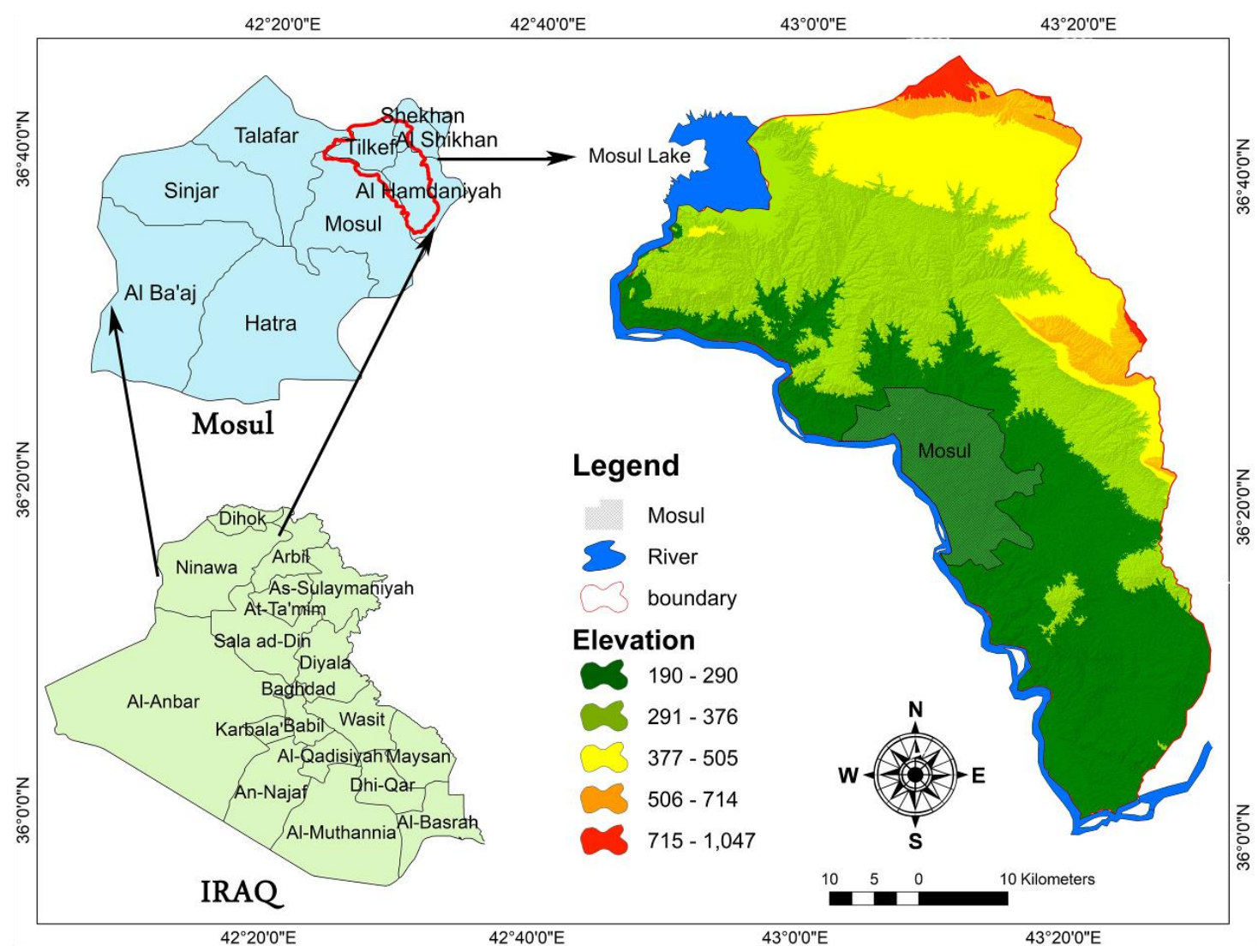

Fig. 1. Location map of Nineveh Plain (the study area)
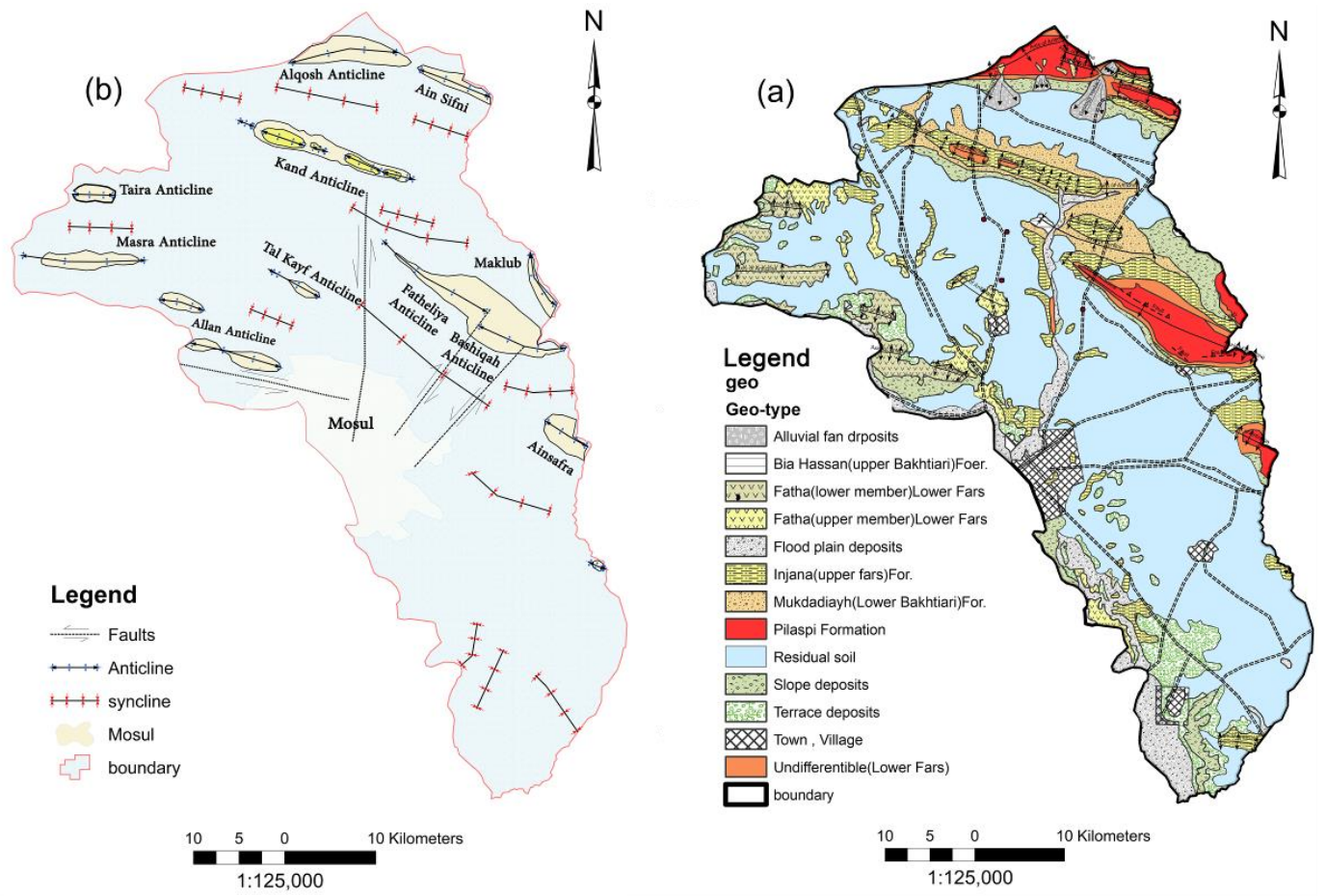

Fig. 2. (a) Geology map; (b) Structural map 


\section{Materials and Methods}

To attain the objective of this study, 69 groundwater samples from various sources such as deep drinking groundwater quality index $\mathrm{g}$ wells, rural wells and drilled wells near sources of pollution were collected in this study during September 2020 (Fig. 3). Ten qualitative parameters have been used to assess the quality and suitability of groundwater for drinking, including: $(\mathrm{pH})$, calcium $\left(\mathrm{Ca}^{2+}\right)$, magnesium $\left(\mathrm{Mg}^{2+}\right)$, sodium $\left(\mathrm{Na}^{+}\right)$, potassium $\left(\mathrm{K}^{+}\right)$, chloride $\left(\mathrm{Cl}^{-}\right)$, sulfate $\left(\mathrm{SO}_{4}^{-}\right)$, bicarbonate $\left(\mathrm{HCO}_{3}^{-}\right)$, nitrate $\left(\mathrm{NO}_{3}^{-}\right)$, and electric conductivity (EC). But it must be said here that absolute concentrations of ions alone are not enough for determining the appropriateness of groundwater to be used for potable water. Therefore, the composite effect of individual parameters of groundwater quality on overall quality was determined by GWQI. Microsoft Excel 2016 was used for computing the weights of groundwater parameters using the entropy method that absolute concentrations of ions alone are not enough for determining the appropriateness of groundwater to be used for potable water. Therefore, the composite effect of individual parameters of groundwater quality on overall quality was determined by GWQI. Microsoft Excel 2016 was used for computing the weights of groundwater parameters using the entropy method Eqs (4) to (9). GWQI calculation consists of four stages: parameters selection, sub-indexes development, and weight assignment, and sub-index aggregation to generate an overall index (Akoteyon, 2013), (Fig. 4). To prevent subjectivity in weight assessment, a system based on information entropy theory was implemented.

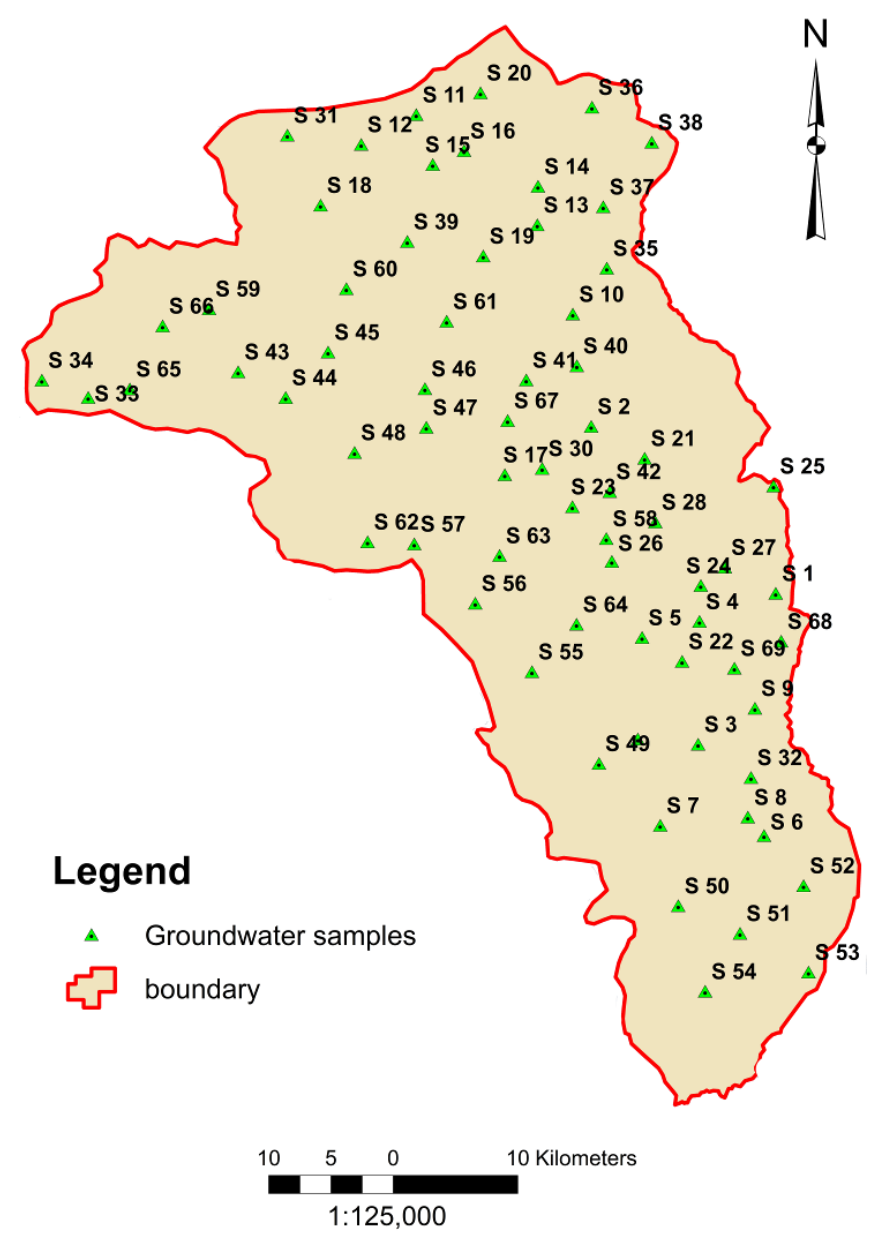

Fig. 3. Locations of the soil samples and field work to take the samples 


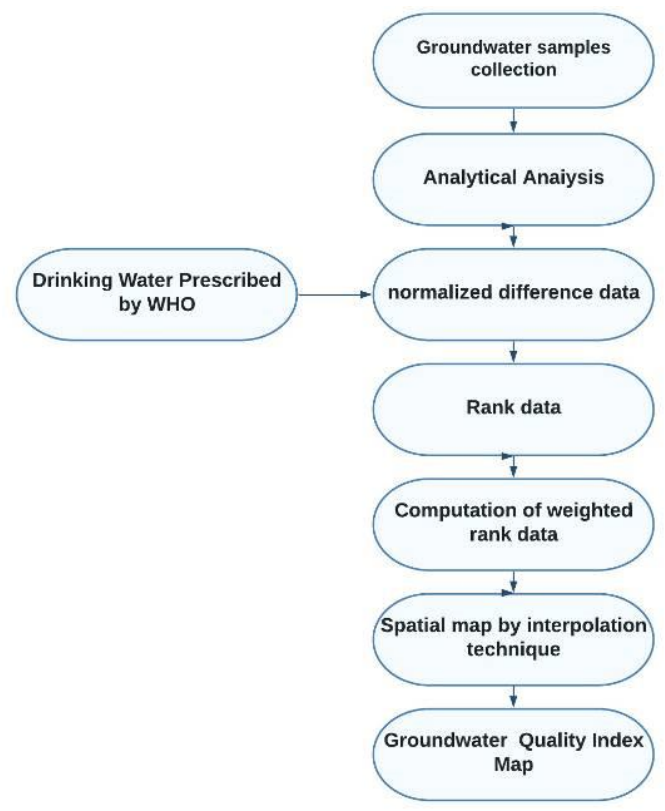

Fig. 4. Flow chart of groundwater quality index

Shannon first suggested the idea of information entropy in 1948 (Shannon, 1948). The information entropy includes the measurement of the degree of disturbance of the system, therefore useful data can be evaluated with the data presented (Yufeng and Fangxiang, 2009). If the value between objects assessed on the same parameter is large, whereas entropy is small, it means more information is available on this parameter and a high weight should be set for this parameter (Qiu, 2002). The comparative weight would be less if the entropy were greater and the difference is smaller. Therefore, the entropy principle offers an objective method for determining weight.

The following are the main stages in determining weights using the entropy method:

- Normalization of the original evaluating matrix. The eight physico-chemical parameters EC, $\mathrm{pH}, \mathrm{Ca}^{2+}, \mathrm{Mg}^{2+}, \mathrm{Na}^{+}, \mathrm{SO}_{4}{ }^{2-}, \mathrm{Cl}^{-}$, and $\mathrm{NO}_{3}^{-}$, which considered to be indications of suitability of groundwater for drinking. Assume $\mathrm{m}$ is the number of groundwater samples that have been collected to evaluate the chemical quality of the region. Chemical components $(j=1,2, n)$ shall be analyzed for any groundwater sample. The $\mathrm{X}$ value matrix can be constructed from the current data:

$$
X=\left[\begin{array}{cccc}
x_{11} & x_{21} & \cdot & x_{1 n} \\
x_{21} & x_{22} & \cdot & x_{2 n} \\
\cdot & \cdot & \cdot & \cdot \\
x_{m 1} & x_{m 2} & \cdot & x_{m n}
\end{array}\right]
$$

A standardized technique must be used to permit for data dimensions and to promote chemical component comparison, (Shi-fei and Zhong-zhi, 2005). In terms of cost (larger values are the better):

$$
y_{i}=\frac{x_{i(\max )}-x_{i}}{x_{i(\max )}-x_{i(\min )}}
$$

While in terms of efficiency (smaller values are the better):

$$
y_{i}=\frac{x_{i}-x_{i(\min )}}{x_{i(\max )}-x_{i(\min )}}
$$

Where:

$i$ : Index or attribute. 
$\boldsymbol{x}_{\boldsymbol{i}}$ : Original value of $\boldsymbol{i}$.

$\boldsymbol{x}_{\boldsymbol{i}(\max )}, \boldsymbol{x}_{\boldsymbol{i}(\min )}$ : Original data, maximum and minimum.

After standardization, the standard matrix $\mathbf{Y}$ may be obtained. Eq. (2) and (3) normalize the data in the range of 0 and 1

$$
Y=\left[\begin{array}{cccc}
y_{11} & y_{21} & \cdot & y_{1 n} \\
y_{21} & y_{22} & \cdot & y_{2 n} \\
\cdot & \cdot & \cdot & \cdot \\
y_{m 1} & y_{m 2} & \cdot & y_{m n}
\end{array}\right]
$$

The index value ratio $(\boldsymbol{j})$ is computed as follows in $(\boldsymbol{i})$ sample :

$$
P_{i j}=\frac{y_{i j}}{\sum_{i=1}^{m} y_{i j}}
$$

- Definition of the entropy

When an analysis involving (n) evaluation indicators and (m) evaluation objects, the concept of entropy of the (j) indicator is defined. The following equation gives the entropy of information:

$$
e_{j}=-\frac{1}{\ln m} \sum_{i=1}^{m} P_{i j} \ln P_{i j}
$$

The smallest value of $\left(\boldsymbol{e}_{\boldsymbol{j}}\right)$ is the largest effect of the $(\boldsymbol{j})$ index.

- Definition of the entropy weight

The entropy weight of the $(j)$ indicator is defined as:

$$
w_{i j}=\frac{1-e_{j}}{\sum_{j=1}^{n}\left(1-e_{j}\right)}
$$

The second stage, the rating scale of quality $(\boldsymbol{q})$ for each groundwater quality parameter must be determined. The estimation $\left(\boldsymbol{q}_{j}\right)$ is as:

$$
q_{j}=\frac{C_{j}}{S_{j}} \times 100
$$

Where $\left(\boldsymbol{C}_{\boldsymbol{j}}\right)$ is the concentration of all chemical components in each sample of groundwater $(\mathrm{mg} / \mathrm{l})$. and $\left(\boldsymbol{S}_{\boldsymbol{j}}\right)$ is the WHO standard (WHO, 2017), Table (2).

The third stage is to use the linear combination technique to calculate GWQI:

$$
G W Q I=\sum_{j=1}^{n} w_{i j} q_{j}
$$

The last stage is to export the calculated GWQI values to the GIS program in a point format and interpolate them with the techniques of Empirical Bayesian kriging to obtain the last GWQI map for the study area.

\section{Results and Discussion}

According to the results of the GWQI that were calculated from the equation (9), five classes classify groundwater, ranging from "excellent water" to "extremely poor water", (Jianhua, Peiyue and Hui, 2011) (Table1). The statistical characteristics of the parameters used in this study is presented in Table 2. The $\mathrm{pH}$ values range from 6.8 to 8.7 (average 7.8), these shows that $\mathrm{pH}$ levels are rather alkaline, T.D.S values ranging from 308.1 to 4923.2 (average $1415.8 \mathrm{mg} / \mathrm{l}$ ), EC values, which is linearly 
related to T.D.S, ranging from 481.4 to 7692.5 (average $2217 \mu \mathrm{m} / \mathrm{cm}$ ). For cations, there was a clear abundance of divalent ions, as calcium concentrations ranged from 24 to 1190 (average $209.9 \mathrm{mg} / \mathrm{l}$ ), $\mathrm{Mg}$ ranges from 4.6 to 970 (average $124.2 \mathrm{mg} / \mathrm{l}$ ). For monovalent ions, $\mathrm{k}$ ranged from 0.3 to 227.3 (average $15.1 \mathrm{mg} / \mathrm{l}$ ), Na ranged from 3.1 to 539.9 (average $91.1 \mathrm{mg} / \mathrm{l}$ ). For negative ions, So ${ }_{4}^{-}$is the most abundant negative ion, ranging from 10.3 to 2270 (average $513.5 \mathrm{mg} / \mathrm{l}$ ), Cl- ranged from 2.9 to 660 (average $166.5 \mathrm{mg} / \mathrm{l}$ ), HCO3- ranged from 17 to 449 (average $282.7 \mathrm{mg} / \mathrm{l}$ ), and No3- from 0.3 to 107.8 (average $31.6 \mathrm{mg} / \mathrm{l}$ ) (Fig. 5).

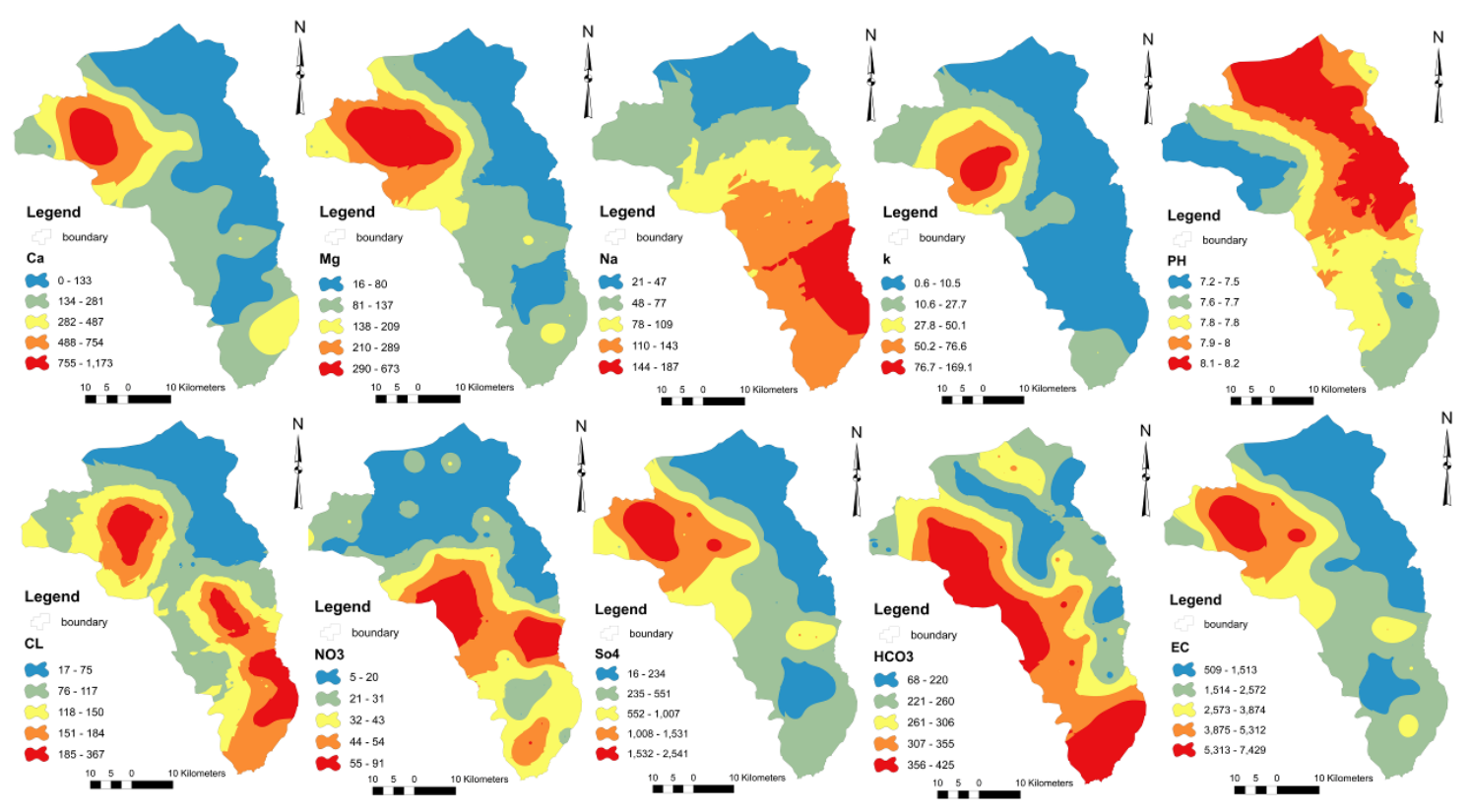

Fig. 5. Distribution of concentrations for $\mathrm{Ca}, \mathrm{Mg}, \mathrm{Na}, \mathrm{K}, \mathrm{PH}, \mathrm{Cl}, \mathrm{NO}_{3}, \mathrm{So}_{4}, \mathrm{HCO}_{3}$, and $\mathrm{EC}$

Table 1. Classification standards of groundwater quality according to GWQI

\begin{tabular}{lcc}
\hline GWQI & Rank & Water quality \\
\hline$<50$ & 1 & excellent \\
$50-100$ & 2 & Good \\
$100-150$ & 3 & Moderate \\
$150-200$ & 4 & Poor \\
$>200$ & 5 & Very poor \\
\hline
\end{tabular}

Table 2. Statistics summary of hydrochemical parameters and WHO standards of drinking water

\begin{tabular}{|c|c|c|c|c|c|}
\hline Chemical parameter & Min & $\operatorname{Max}$ & Mean & SD & WHO Standard \\
\hline $\mathrm{EC} \mu \mathrm{m} / \mathrm{cm}$ & 481.4 & 7692.5 & 2217 & 1832 & 500 \\
\hline T.D. S & 308.1 & 4923.2 & 1415.8 & 1174 & 600 \\
\hline $\mathrm{PH}$ & 6.81 & 8.7 & 7.8 & 0.5 & $6.5-8.5$ \\
\hline $\mathrm{Ca} \mathrm{mg} / \mathrm{l}$ & 24 & 1190 & 209.9 & 258 & 250 \\
\hline $\mathrm{Mg} \mathrm{mg/l}$ & 4.62 & 970 & 124.2 & 179.5 & 50 \\
\hline $\mathrm{Na} \mathrm{mg} / \mathrm{l}$ & 3.1 & 539.9 & 91.1 & 106.9 & 200 \\
\hline $\mathrm{K}$ mg/l & 0.3 & 227.3 & 15.1 & 43.4 & 20 \\
\hline CL mg/l & 2.9 & 660 & 116.5 & 137.2 & 250 \\
\hline $\mathrm{NO}_{3} \mathrm{mg} / \mathrm{l}$ & 0.3 & 107.8 & 31.6 & 27.7 & 50 \\
\hline $\mathrm{SO}_{4} \mathrm{mg} / \mathrm{l}$ & 10.3 & 2710 & 513.5 & 666.7 & 250 \\
\hline $\mathrm{HCO}_{3} \mathrm{mg} / 1$ & 17 & 449 & 282.7 & 108.9 & 500 \\
\hline
\end{tabular}


After calculating the weights of groundwater coefficients using the entropy method (Table 3), the results are clarified to show that the highest weight of the entropy belonged to the T.D.S (0.53228), followed by $\mathrm{pH}(0.15347), \mathrm{NO}_{3}(0.08663), \mathrm{SO}_{4}(0.06891)$, and $\mathrm{Ca}(0.04956)$. The lowest entropy weight for $\mathrm{Cl}, \mathrm{Na}$, and $\mathrm{Mg}$ was $0.04295,0.03667$, and 0.02952 , respectively

Table 3. Results of information entropy and weight

\begin{tabular}{lccc}
\hline Factors & ej & 1-ej & wij \\
\hline T.D.S & 0.89652 & 0.10348 & 0.53228 \\
$\mathrm{PH}$ & 0.97016 & 0.02984 & 0.15347 \\
$\mathrm{Ca}$ & 0.99037 & 0.00963 & 0.04956 \\
$\mathrm{Mg}$ & 0.99426 & 0.00574 & 0.02952 \\
$\mathrm{Na}$ & 0.99287 & 0.00713 & 0.03667 \\
$\mathrm{CL}$ & 0.99165 & 0.00835 & 0.04295 \\
$\mathrm{No} 3$ & 0.98316 & 0.01684 & 0.08663 \\
$\mathrm{So}_{4}$ & 0.98660 & 0.01340 & 0.06891 \\
\hline
\end{tabular}

Eq. 8 was applied to determine the quality rate $\mathrm{q} j$ of every parameter after obtaining the weights. Finally, The GWQI was calculated for each borehole using Eq. 9. The categories of groundwater quality are based on the calculated GWQI values. The GWQI values range between (48-581.8). These values were divided into five categories manually (Jianhua, Peiyue and Hui, 2011), as shown in Tables 4 and 5: Excellent $(<50)$, good $(50-100)$, medium $(100-150)$, poor $(150-200)$, and very poor $(>200)$. The excellent class extends over an area of $50.9 \mathrm{~km}^{2}(0.2 \%$ from the study area), which represents the Sheikhan area, specifically, in the Ain Sifni fold. The good class covered $596 \mathrm{~km}^{2}(23.4 \%$ of the study area), and extends from the east towards the northeast within the folds area, which is located within the Pilaspi formation, It is one of the freshest and most abundant aquifers in the study area where considered recharge areas for groundwater. The medium class covered $473.7 \mathrm{~km}^{2}$ (18.6\% of the study area), this region is located in the central and southern sections of the study area, in the transition zone between folds and flat areas. Finally, the poor and very poor classes occupy $26.1 \%, 31.7 \%\left(664.8 \mathrm{~km}^{2}, 807 \mathrm{~km}^{2}\right)$ respectively (Table (4). It is located within the northwest and west of the study area, represented by the city centre of Mosul, (Fig. 6).

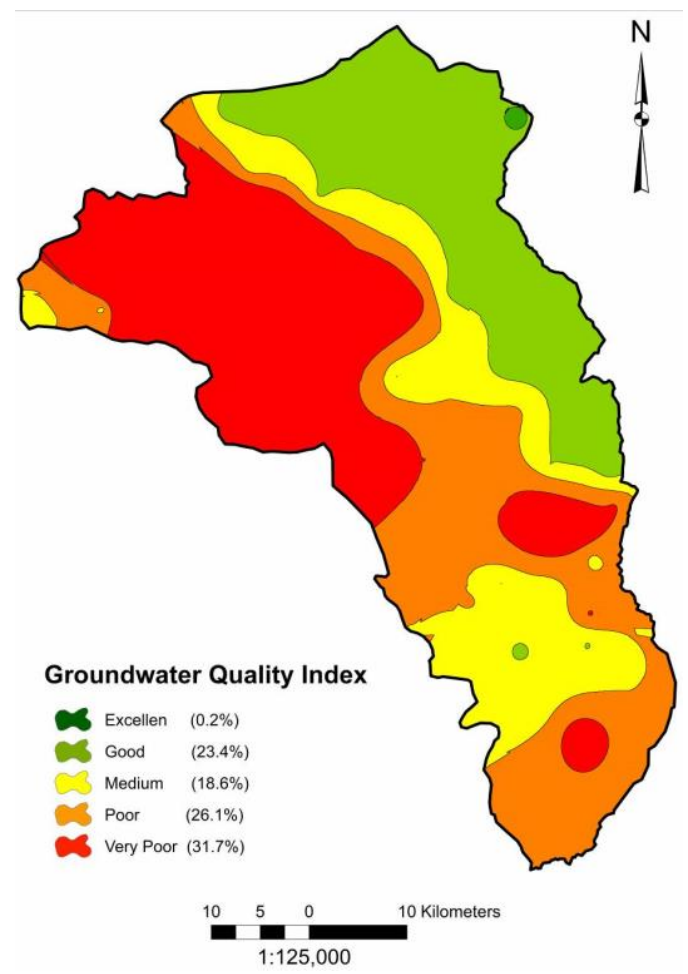

Fig. 6. Groundwater quality index map 
Table 4. Areas occupied by GWQI zones

\begin{tabular}{lccc}
\hline GWQI range & GWQI zone & Area $\left(\mathbf{k m}^{\mathbf{2}}\right)$ & Area $(\boldsymbol{\%})$ \\
\hline$<50$ & Excellent & 50.9 & 0.2 \\
$50-100$ & Good & 596 & 23.4 \\
$100-150$ & Moderate & 473.7 & 18.6 \\
$150-200$ & Poor & 664.8 & 26.1 \\
$>200$ & Very poor & 807 & 31.7 \\
\hline
\end{tabular}

Table 5. EWQI value and quality rank of samples based on WHO

\begin{tabular}{|c|c|c|c|c|c|c|c|c|}
\hline Name & GWQI & GWQI Class & Name & GWQI & GWQI Class & Name & GWQI & GWQI Class \\
\hline S 1 & 50.0 & Excellent & S 24 & 89.2 & Good & S 47 & 225.6 & Extremely poor \\
\hline S 2 & 149.3 & Moderate & S 25 & 60.6 & Good & S 48 & 360.4 & Extremely poor \\
\hline S 3 & 115.2 & Moderate & S 26 & 179.0 & Poor & S 49 & 165.5 & Poor \\
\hline S 4 & 196.6 & Poor & S 27 & 58.7 & Good & S 50 & 100.6 & Moderate \\
\hline S 5 & 198.2 & Poor & S 28 & 178.6 & Poor & S 51 & 281.4 & Extremely poor \\
\hline S 6 & 101.0 & Moderate & S 29 & 88.8 & Good & S 52 & 150.9 & Poor \\
\hline S 7 & 88.2 & Good & S 30 & 96.3 & Good & S 53 & 158.5 & Poor \\
\hline S 8 & 83.6 & Good & S 31 & 62.8 & Good & S 54 & 185.2 & Poor \\
\hline S 9 & 115.6 & Moderate & S 32 & 228.8 & Extremely poor & S 55 & 154.3 & Poor \\
\hline S 10 & 88.4 & Good & S 33 & 150.6 & Poor & S 56 & 260.2 & Extremely poor \\
\hline S 11 & 74.2 & Good & S 34 & 115.7 & Moderate & S 57 & 243.0 & Extremely poor \\
\hline S 12 & 101.2 & Moderate & S 35 & 61.2 & Good & S 58 & 188.0 & Poor \\
\hline S 13 & 78.3 & Good & S 36 & 59.2 & Good & S 59 & 581.8 & Extremely poor \\
\hline S 14 & 82.9 & Good & S 37 & 51.2 & Good & S 60 & 457.6 & Extremely poor \\
\hline S 15 & 81.4 & Good & S 38 & 46.0 & Excellent & S 61 & 204.6 & Extremely poor \\
\hline S 16 & 89.8 & Go & S 39 & 68.5 & Good & S 6 & 206.5 & Extremely poor \\
\hline S 17 & 4.6 & Go & S 40 & 58. & Good & $\mathrm{S} \epsilon$ & 239.9 & Extremely poor \\
\hline S 18 & 94.1 & Good & S 41 & 264.7 & Extremely poor & S 6 & 166.6 & Poor \\
\hline S 19 & 102.4 & Moderate & S 42 & 124.4 & Moderate & S 65 & 108.8 & Moderate \\
\hline S 20 & 82.9 & Good & S 43 & 533.0 & Extremely poor & S 66 & 458.4 & Extremely poor \\
\hline S 21 & 53.8 & Good & S 44 & 472.1 & Extremely poor & S 67 & 209.3 & Extremely poor \\
\hline S 22 & 331.9 & Extremely poor & S 45 & 309.5 & Extremely poor & S 68 & 223.1 & Extremely poor \\
\hline S 23 & 155.4 & Poor & S 46 & 581.3 & Extremely poor & S 69 & 298.8 & Extremely poor \\
\hline
\end{tabular}

Through the results listed in Table 2, which show increase in the electrical conductivity, west and south of the study area. This increase is due to the high concentration of sulfate and magnesium ions, which are above the permissible levels within the WHO for drinking water, especially in the wells located within the Fatha Formation, which exposing in the surface towards the west and northwest. In addition, an increase in nitrates can be observed in the wells close to urban areas as a result of leakage of sewer pipes and detached houses without sewer systems. On other hand, there is a clear increase in the concentration of calcium and magnesium in the wells located north-east of the study area, where the formation of the Pilaspi is located. The effect of geological formations on increasing the concentration of ions that have a natural origin in these formations can be observed. By comparing the geological map (Fig. 2a) with the water quality map (Fig. 6), it is possible to demonstrate this, It has also been proven by analysis of entropy results and weights that gave the greatest effect of sulfates in the first degree, then followed by nitrates in the second degree, then calcium in the third degree, followed by the rest of the other ions.

\section{Conclusions}

Ground water quality in Nineveh Plain shows spatial variation according to the final map (Fig. 6). In the Nineveh Plain, the water quality was affected by urban, agricultural, and industrial activities. The contribution of $\mathrm{SO}_{4}, \mathrm{Ca}$, and $\mathrm{NO}_{3}$ ions in rising the $\mathrm{EC}$ and in influencing the change of groundwater 
quality is greater than the rest of the ions that have a slight effect on changing the quality of groundwater. This is clear in the central and northern regions as a result of population activity and an increase in the concentration of sulfate and salts, and this is what made the classification of most samples into four categories (good, medium, poor, and very poor). Furthermore, the Pilaspi Formation is characterized by increased infiltration processes because it contains many cracks and fractures, so the water has a good quality because of its proximity to the feeding areas. According to the WQI classification, $42.2 \%$ of the groundwater in the study region are drinkable; however, this number is critical if groundwater is frequently used and all causes of surface contamination are monitored and prevented by the responsible authorities.

\section{Acknowledgements}

The authors are very grateful to the reviewers, Editor in Chief Prof. Dr. Salih M. Awadh, the Secretary of Journal Mr. Samir R. Hijab, and the Technical Editors for their great efforts and valuable comments.

\section{References}

Ahmad, M. A, 1980. Geology of Shaikhan Area. Unpublished M. Sc Thesis, College of Science, University of Mosul.

Akoteyon, I. S, 2013. Evaluation of groundwater quality using water quality indices in parts of Lagos-Nigeria. Journal of Environmental Geography, 6(1-2), 29-36.

Al-Abadi, A. M., Fryar, A. E., Rasheed, A. A., \& Pradhan, B. 2021. Assessment of groundwater potential in terms of the availability and quality of the resource: a case study from Iraq. Environmental Earth Sciences, 80(12), 1-22.

Al-Jiburi, H. K. S, 2007. Hydrogeological and Hydrochemical Study of Mosul Quadrangle Sheet (NJ-38-13).

Al-Jumaily, I. S. I. and Al-Azzawi, A. G, 2018. Structural and tectonic analysis of Bashiqa and AL-Fadhlya Anticlines-Northern Iraq. Iraqi National Journal of Earth Sciences, 18(1), 87-116.

Alozeer, A., Abdaki, M. A., Al-Iraqi, A., Al-Samman, S., \& Al-Hammadi, N., 2020. Estimation of mean areal rainfall and missing data by using gis in nineveh, Northern Iraq. The Iraqi Geological Journal, 93-103.

Ameen, M. A, 2006. Sedimentological characteristics of transitional zone between marine-non marine Miocene Sediments in selected sections-Northern Iraq. Tikrit Journal of Pure Science, 11(1).

Anderson, M. P., Woessner, W. W. and Hunt, R. J, 2015. Applied groundwater modeling: simulation of flow and advective transport. Academic press.

Awadh, S.M. and Ahmed, R.M., 2013. Hydrochemistry and pollution probability of selected sites along the Euphrates River, Western Iraq. Arabian Journal of geosciences, 6(7), 2501-2518.

Awadh, S.M., Al-Mimar, H. and Yaseen, Z.M., 2021. Groundwater availability and water demand sustainability over the upper mega aquifers of Arabian Peninsula and west region of Iraq. Environment, Development and Sustainability, 23(1), 1-21.

Beg, A. A. F., Awadh, S. M., Thamer, M. B., \& Al-Sulttani, A. H., 2021. Assessment of Groundwater Quality for Drinking Purposes Using Water Quality Index, and Identifying the Affecting Mechanism in Rashdiya, Central Iraq. The Iraqi Geological Journal, 20-32.

Chatterjee, R., Tarafder, G. and Paul, S, 2010. Groundwater quality assessment of Dhanbad district, Jharkhand, India. Bulletin of Engineering Geology and the Environment, 69(1), 137-141.

Fatah, K. K., Hamed, M., Saeed, M. H., \& Dara, R., 2020. Evaluation groundwater quality by using GIS and water quality index techniques for wells in Bardarash area, Northern Iraq. The Iraqi Geological Journal, 87-104.

Gain, A. K., Giupponi, C. and Wada, Y, 2016. Measuring global water security towards sustainable development goals. Environmental Research Letters, 11(12), 124015.

Giri, S, 2020. Water quality prospective in Twenty First Century: Status of water quality in major river basins, contemporary strategies and impediments: A review. Environmental Pollution, 116332.

Hussein, R. A. and Al-Salem, T. H. A, 2017. Hydrochemistry and Water Quality for Alqosh-Kand Catchment Area North of Mosul, North of Iraq. kirkuk University Journal for Scientific Studies, 12(1). 
Jiang, Y, 2009. China's water scarcity. Journal of environmental management, 90(11), 3185-3196.

Jianhua, W., Peiyue, L. and Hui, Q, 2011. Groundwater quality in Jingyuan County, a semi-humid area in Northwest China. Journal of Chemistry, 8(2), 787-793.

Lintern, A., Webb, J. A., Ryu, S., Liu, U., Bende, D., Waters, P., Leahy, P., Wilson, P., Western, A., 2018. Key factors influencing differences in stream water quality across space. Wiley Interdisciplinary Reviews: Water, 5(1), 1260.

Mateo-Sagasta, J., Zadeh, S. M., Turral, H., \& Burke, J., 2017. Water pollution from agriculture: a global review. Executive summary.

Mustafa, M. M. and Alian, Y. J, 2013. Geological site investigation between the Mosul and Badush dams (North Iraq) from of the resistivity tomography. Iraqi Geology and Mining Journal, 24.

Mutib, M. and Al-shaikh, Z. D, 2005. New contribution to the Geology of Mosul Area from geoelectric investigations. Rafidain Journal of Science, 16(6), 132-147.

Pei-Yue, L., Hui, Q. and Jian-Hua, W. U, 2010. Groundwater quality assessment based on improved water quality index in Pengyang County, Ningxia, Northwest China. E-Journal of Chemistry, 7(S1), S209-S216.

Qiu, W, 2002. Management decision and applied entropy. Science,, China Machine Press, Beijing, China.

Rashid, A. A., Al-Dabbas, M. A. and Kadhim, W. H, 2016. Assessment of groundwater quality for drinking in Tuz Khurmatu Area, Salahadden Governorate, Iraq. The Iraqi Geological Journal, 91-103.

Reza, R. and Singh, G, 2010. Assessment of ground water quality status by using Water Quality Index method in Orissa, India. World Applied Science Journal, 9(12), 1392-1397.

Shannon, C. E, 1948. A mathematical theory of communication. The Bell System Technical Journal, 27(3), 379-423.

Shi-fei, D. and Zhong-zhi, S, 2005. Studies on incidence pattern recognition based on information entropy. Journal of Information Science, 31(6), 497-502.

Talabi, A. O. and Kayode, T. J, 2019. Groundwater pollution and remediation. Journal of Water Resource and Protection, 11(01), 1.

Yufeng, S. and Fengxiang, J, 2009. Landslide stability analysis based on generalized information entropy. International Conference on Environmental Science and Information Application Technology. IEEE, 83-85. 